\title{
Análise das Práticas de Gestão do Conhecimento de Empresas do Setor Farmacêutico no Brasil
}

\author{
Carmen Cunha ${ }^{1}$ \\ Maria Celeste Vasconcelos ${ }^{2}$ \\ Tarcisio Afonso ${ }^{3}$
}

\section{RESUMO}

Este artigo descreve uma pesquisa com 18 empresas do setor farmacêutico que foram eleitas como as melhores empresas para se trabalhar no Brasil, pelo guia Exame/Você 2004. O objetivo da pesquisa foi identificar as práticas compatíveis com a gestão do conhecimento utilizadas por estas empresas e verificar se elas procuram equilibrar práticas formais e informais. Para a coleta de dados foi utilizada a estratégia de levantamento nos documentos das empresas e em revistas especializadas. A amostra foi composta por $67 \%$ de empresas de grande porte e $33 \%$ de empresas de médio porte, com predominância do capital estrangeiro. A análise dos resultados revelou que a criação e manutenção de um ambiente aberto, de camaradagem e de estímulo à criatividade e à iniciativa, representam algumas das práticas mais presentes.

PALAVRAS-CHAVE: gestão do conhecimento; setor farmacêutico; práticas formais e informais; boas ideias, capacidade de inovação.

\begin{abstract}
This paper describes a research with 18 pharmaceutical sector companies, voted as the best to work with in Brazil, by the Guide Exame/Você 2004. The research plan was to identify the practices according with the knowledge management used by these companies and also verify if they try to balance formal and informal practices. For the data collection was used the strategy to scan the enterprises documents and specialized publications. The sample was composed of $67 \%$ of large companies, and $33 \%$ of medium sized ones, with predominance of foreign capital. The analysis of the resulting data revealed that the creation and maintenance of an open environment, of companionship and incentive for creativity and initiative, represent some of the most present practices.
\end{abstract}

KEY-WORDS: knowledge management; pharmaceutical sector; formal and informal practices; good ideas; innovation capability.

\section{INTRODUÇÃO}

No mundo globalizado, as mudanças acontecem de forma acelerada, os consumidores são mais exigentes, os produtos são cada vez mais abundantes, de maior qualidade, com um ciclo de vida

\footnotetext{
${ }^{1}$ Analista da IBM do Brasil, unidade Belo Horizonte, fone: 3343-1272 e 9612-7281; R. Biagio Polizzi, 257/301; Bairro Silveira - CEP. 31140-500, Belo Horizonte - MG, carmencunha2003@yahoo.com.br

${ }^{2}$ Professora do Mestrado Profissional em Administração da Fundação Pedro Leopoldo, fone: 31 3686-1461; Av. Lincoln Diogo Viana, 830, Bairro Dr. Lund, CEP. 33.600-000, Pedro Leopoldo - MG, celestevasconcelos@ gmail.com

${ }^{3}$ Professor do Mestrado Profissional em Administração da Fundação Pedro Leopoldo, fone: 31 3686-1461; Av. Lincoln Diogo Viana, 830, Bairro Dr. Lund, CEP. 33.600-000, Pedro Leopoldo - MG, afonso@allportal.com.br
} 
mais curto. Este dinamismo do mercado faz com que as organizações busquem adotar ferramentas gerenciais eficientes visando garantir a sua competitividade e até mesmo a sua sobrevivência.

Neste contexto, o conhecimento passou a ser visto como diferencial competitivo e expressões como sociedade da informação, sociedade do conhecimento e economia do conhecimento tornaram-se comuns no âmbito empresarial. Cavalcanti, Gomes e Pereira (2001) destacam que a crescente redução dos custos e a facilidade de obtenção de informação indicam o incremento da participação do conhecimento na geração de riqueza em organizações, regiões e países.

De acordo com Davenport (1999, p. 20):

A vantagem do conhecimento é sustentável porque gera retornos crescentes e novas perspectivas de operação. Ao contrário dos ativos materiais, que diminuem à medida que são usados, os ativos do conhecimento aumentam com o uso: ideias geram novas ideias e o conhecimento compartilhado permanece com o doador ao mesmo tempo que enriquece o recebedor.

Percebe-se que a capacidade de gerar conhecimentos, inovação e empreender são condições para o sucesso nessa nova economia. Para Graham e Pizzo (1998), a gerência eficaz do conhecimento consiste na capacidade de equilibrar atividades que cultivam as matérias-primas da mente com a execução disciplinada, necessária para transformar boas ideias em mercadorias de valor. Neste cenário, a gestão do conhecimento tem sido apontada como sendo fundamental para a estratégia empresarial.

\section{GESTÃO DO CONHECIMENTO}

O conceito de gestão do conhecimento tem fundamentação multidisciplinar - ancorada nas ciências cognitivas, na administração e na informação. Envolve inúmeros processos destinados a fomentar a cultura do conhecimento coletivo dentro das organizações. De acordo com Cavalcanti, Gomes e Pereira (2001, p. 153), "gerenciar conhecimento é mais do que gerenciar fluxos de informação. Significa alimentar o fogo criativo do autoquestionamento dos colaboradores que integram as organizações. O conhecimento que guia uma empresa para o sucesso não vem somente das mentes de seus colaboradores, mas também de seus corações".

Segundo Terra (2001), a gestão do conhecimento pode ser entendida a partir de sete dimensões da prática gerencial:

a) O papel indispensável da alta administração na definição dos campos de conhecimento, nos quais os funcionários da organização devem focalizar seus esforços de aprendizado, além do seu papel indispensável na clarificação da estratégia empresarial e na definição de metas desafiadoras e motivantes.

b) O desenvolvimento de uma cultura organizacional voltada à inovação, à experimentação, ao aprendizado contínuo e comprometida com os resultados de longo prazo e com a otimização de todas as áreas da empresa deve ser uma das preocupações fundamentais da alta administração. Neste sentido, as escolhas em termos de normas formais e informais a serem estimuladas e apoiadas adquirem um caráter altamente estratégico. A cultura organizacional torna-se, ademais, fundamental para o desenvolvimento estratégico à medida que o próprio conceito de estratégia perde o seu caráter tradicional, determinista e de posicionamento e ganha um caráter muito mais de ação e tolerância ao erro, tático, de alavancagem baseada em habilidades centrais e de formação de alianças.

c) As novas estruturas organizacionais e práticas de organização do trabalho, que diversas empresas estão adotando para superar os limites à inovação, ao aprendizado e à geração de 
novos conhecimentos, impostos pelas tradicionais estruturas hierárquico-burocráticas. Em grande medida, estas novas estruturas estão baseadas no trabalho de equipes multidisciplinares com alto grau de autonomia.

d) As práticas e políticas de administração de recursos humanos associadas à aquisição de conhecimentos externos e internos à empresa, assim como à geração, difusão e ao armazenamento de conhecimentos na empresa. Destacam-se, em particular, as seguintes iniciativas: melhorar a capacidade das organizações de atrair e de manter pessoas com habilidades, comportamentos e competências que adicionam aos estoques e aos fluxos de conhecimento das mesmas. Estimular comportamentos alinhados com os requisitos dos processos individual e coletivo de aprendizado, assim como aqueles que resguardem os interesses estratégicos e de longo prazo da empresa no que tange ao fortalecimento de suas core competencies. Neste sentido são destacados planos de carreira e treinamentos que ampliam as experiências, assim como contatos e interações com outras pessoas de dentro e de fora da empresa; adotar esquemas de remuneração, cada vez mais, associados à aquisição de competências individuais, ao desempenho da equipe e da empresa como um todo no curto e no longo prazo.

e) Os avanços na informática, nas tecnologias de comunicação e nos sistemas de informação estão afetando os processos de geração, difusão e armazenamento de conhecimento nas organizações. Reconhecem-se as novas possibilidades propiciadas pelo avanço tecnológico, mas o papel do contato pessoal e do conhecimento tácito para os processos de aprendizado organizacional, assim como a manutenção de um ambiente de elevada confiança, transparência e colaboração, ainda são considerados essenciais. Os melhores sistemas de informação e ferramentas de comunicação ainda dependem essencialmente dos inputs individuais.

f) Esforços recentes de mensuração de resultados sob várias perspectivas e em sua comunicação por toda a organização. Destacam-se, em particular, esforços recentes de autores e empresas preocupadas em avaliar várias dimensões do capital intelectual.

g) A crescente necessidade de as empresas se engajarem em processos de aprendizado com o ambiente e, em particular, por meio de alianças com outras empresas e do estreitamento do relacionamento com clientes.

Terra (2001, p. 12) complementa dizendo que

é evidente que subjacente à maior parte destas dimensões está o reconhecimento de que o capital humano, formado pelos valores e normas individuais e organizacionais, bem como pelas competências, habilidades e atitudes de cada funcionário, é a "mola propulsora" da geração de conhecimentos e geração de valor nas empresas.

Fleury e Fleury (2000) citam alguns dos processos que proporcionam a disseminação do conhecimento por toda empresa:

a) Comunicação e circulação de conhecimentos: o conhecimento precisa circular de maneira rápida e eficiente pela organização; novas ideias têm maior impacto quando compartilhadas coletivamente do que quando são propriedade de poucas pessoas.

b) Treinamento: talvez essa seja a forma mais utilizada de pensar o processo de aprendizagem e disseminação de novas competências.

c) Rotação de pessoas: por áreas, unidades e posições na empresa, de forma a vivenciar novas situações de trabalho e compreender a contribuição das diferentes posições para o sistemaempresa.

d) Trabalho em equipes diversas: o processo de integração com pessoas de background diferente (seja em termos de origem, de formação, de experiência profissional) propicia a disseminação de ideias, propostas e soluções inovadoras para os problemas organizacionais.

Sobre a rotação de pessoas, Souza Neto (2004, p. 55) acrescenta: 
Uma das melhores formas de se difundir o conhecimento tácito, que, como se sabe, é especialmente difícil de ser socializado, é a transferência de pessoas para áreas onde possam fazer uso do que aprenderam. A técnica do rodízio é particularmente benéfica nessas situações. Ao mudar para uma nova atividade, o funcionário leva consigo tudo o que aprendeu na função anterior. É uma tendência natural, empregar as práticas que considerar mais adequadas no novo desafio. Se há um encadeamento entre as duas atividades, isso pode ser observado ainda mais facilmente. Ao assumir a nova função, estará mais apto a compreender melhor a forma como o trabalho do novo departamento impactará o outro e, tendo a abertura necessária, vai procurar melhorar as práticas do setor, visando uma contribuição mais efetiva. Nesse processo reside a difusão do conhecimento.

\section{AMBIENTE DE APRENDIZAGEM}

Segundo Senge (1990), o ser humano nasce com a motivação para aprender, explorar e a experimentar. $\mathrm{O}$ que muitas vezes limita esta motivação são as instituições que estão orientadas para o controle.

Para Garvin (2001, p. 54), “a organização que aprende é a que dispõe de habilidades para criar, adquirir e transferir conhecimentos, e é capaz de modificar seu comportamento, de modo a refletir novos conhecimentos e idéias". O autor observa que as organizações que aprendem cultivam a arte de ouvir com abertura e atenção. Os gerentes devem manter-se receptivos a críticas. $\mathrm{O}$ autor esclarece que, para ser uma organização que aprende, ela deve possuir:

a) ambiente propício à aprendizagem;

b) disponibilidade de tempo para reflexão e análise, para pensar sobre os planos estratégicos, dissecar as necessidades dos clientes, avaliar os atuais sistemas de trabalho e inventar novos produtos;

c) abertura de fronteiras e estímulo ao intercâmbio de ideias;

d) promoção de fóruns de aprendizado.

Terra (2001) cita alguns sinais de um ambiente propício para o constante aprendizado e desenvolvimento de competências:

a) as pessoas se sentem estimuladas pelo próprio trabalho;

b) as pessoas conversam umas com as outras, incluindo aquelas de diferentes níveis hierárquicos;

c) as relações são informais;

d) as pessoas têm tempo para aprender;

e) as pessoas não estão focadas apenas em sua área de trabalho e no curto prazo;

f) as pessoas falam abertamente sobre os erros passados e as lições aprendidas;

g) a empresa tem facilidade em atrair e manter os melhores talentos, mesmo sem pagar, necessariamente, acima do mercado;

h) a atitude é uma das principais características avaliadas na contratação de pessoal;

i) os muitos indicadores de resultados são amplamente divulgados;

j) a discussão dos valores da organização é vista como algo altamente relevante.

\section{PRÁTICAS DE GESTÃo DO CONHECIMENTO}

Para Davenport e Prusak (1998, p. 46), "a gestão do conhecimento se baseia nos recursos existentes, com os quais a organização já pode contar - uma boa gestão de sistemas de informação, uma gestão da mudança organizacional e boas práticas da gestão de recursos humanos". Se a organização tem uma boa biblioteca, um sistema de banco de dados textuais ou até mesmo programas educativos 
eficazes, provavelmente a empresa já está fazendo alguma coisa que poderia ser chamada de gestão do conhecimento.

Brown e Duguid (2001) observam que mesmo as pessoas envolvidas em práticas de trabalho aparentemente rotineiras têm de ser criativas porque o mundo em que trabalham muda rapidamente. Suas rotinas são sempre um pouco desordenadas. Precisam improvisar para compensar a diferença entre as condições para as quais suas rotinas foram projetadas, e as condições reais, impostas pelo mundo em mudanças. Para os autores, todas as melhores práticas do cotidiano, individualmente insignificantes, espalhadas pela empresa, somam enorme volume de conhecimentos.

Brown e Duguid (2001) observam que identificar as melhores práticas de uma empresa não é fácil, por duas razões. Primeiro, há uma grande lacuna entre a tarefa contida no manual de processo e a realidade. Segundo, há uma lacuna entre o que as pessoas acham que fazem e o que fazem de fato. As práticas de trabalho reais estão repletas de improvisações tácitas que os empregados que as desempenham teriam dificuldade em articular. $\mathrm{O}$ gestor que desejar entender as melhores práticas da empresa precisa fechar ambas as lacunas. Os autores enumeram as finalidades da prática de narração de histórias, experimentação e improvisação dentro do ambiente da organização. A narração constante de histórias sobre problemas e soluções, desastres e triunfos, durante o café da manhã, almoço e cafezinhos tem inúmeras finalidades sobrepostas. Histórias são ótimas para apresentar situações em sequência (aconteceu isso, depois aquilo). Elas também apresentam as situações casualmente (aconteceu em consequência daquilo). Portanto, as histórias são formas poderosas de se entender o que é e por que aconteceu. A narração de histórias ajuda-nos a descobrir novidades sobre o mundo e nos permite compartilhá-las com os demais. Finalmente, a narração ajuda aqueles que compartilham a história a desenvolver uma visão comum. Ressalta-se que nem todos os problemas conseguem ser resolvidos durante o café da manhã ou por meio da narração de histórias. A experimentação e improvisação também são essenciais.

\section{BUSCANDO O EQUILÍBRIO}

Graham e Pizzo (1998) afirmam que a essência da gerência eficaz do conhecimento reside na capacidade de equilibrar atividades criativas que cultivam as matérias-primas da mente com a execução disciplinada necessária para transformar boas ideias em mercadorias de valor.

No domínio fluido (informal), o conhecimento se origina e cresce a partir da intuição pessoal, redes pessoais que se formam fora dos organogramas formais, encontros casuais entre pessoas e a improvisação, que desconhecem procedimentos-padrão para descobrir maneiras melhores de se fazerem as coisas.

No domínio institucional (formal), o trabalho é estruturado, controlado e medido. O conhecimento é claramente definido em procedimentos, relatórios, memorandos e bases de dados. Geralmente é compartilhado seletivamente através das linhas de comando oficiais.

Brown e Duguid (2001, p. 49) corroboram essas afirmativas acrescentando que

os processos de cima para baixo destinados a institucionalizar novas ideias podem ter um efeito assustador sobre a criatividade. Mas não precisa ser assim. Os gerentes são capazes de aprender a lidar com tênue linha entre a rigidez - que reprime a criatividade - e o caos onde a criatividade flui livremente e nada chega ao mercado.

Graham e Pizzo (1998) ressaltam que, se o ambiente for demasiadamente fluido, o trabalho criativo não terá uma conexão sólida com as metas de negócios e a responsabilidade não será clara. Como resultado, muitas excelentes ideias jamais chegam ao mercado. Por outro lado, demasiada formalidade sufoca a iniciativa e o compromisso aberto necessários para a concepção de produtos e serviços singulares e para o rápido aproveitamento de novas ideias. 
Brown e Duguid (2001) também são da opinião de que, se pendermos muito para a prática, novas ideias podem surgir e se evaporar por falta de uma estrutura que as controle. Se pendermos demais para o processo, teremos muita estrutura, mas pouquíssima liberdade de movimento para dar origem à centelha inicial das ideias. Encontrar o equilíbrio é tarefa central para gerentes de toda parte - está incorporada em milhões de modismos empresariais e transcende a todos.

Graham e Pizzo (1998) consideram que a alternativa é gerenciar com a disciplina-apenas-suficiente (JED - Just-Enough-Discipline) para manutenção do equilíbrio correto entre os domínios fluido e institucional. Dessa forma, uma empresa está constantemente ajustando o mix de liberdade e o controle visando alcançar inovação, flexibilidade e eficiências operacionais necessárias ao sucesso no complexo mercado atual. Os autores afirmam que as empresas que estão na vanguarda da aprendizagem identificam metas de gestão da aprendizagem ou do conhecimento como elementos explícitos da estratégia corporativa. A clara articulação de valores e propósitos de negócios e sua gestão centralizada permitem que o ambiente fluido floresça. A burocracia é mínima, comunidades de práticas florescem e o compartilhamento de conhecimento e informação é amplo e eficiente. A ênfase em liderança baseada em valores libera claramente indivíduos de excessiva gerência de comando-e-controle. Ao mesmo tempo, medições de desempenho, em estreita correlação com valores essenciais e metas de negócios, impõem responsabilidade operacional e financeira.

Para Graham e Pizzo (1998, p. 130):

O desafio mais crítico nos negócios da nova economia é o de criar os contextos sociais que maximizam a criatividade e a produtividade humanas. Verificamos que as empresas com os históricos mais sustentáveis compartilham desta crença. Essas organizações são flexíveis, inovadoras e eficazes porque suas pessoas o são.

Nonaka (1997, p. 29) afirma que: "A chave do processo é o comprometimento pessoal, o senso de identificação dos funcionários com a empresa e sua missão.”

\section{REALIZAÇÃO DA PESQUISA DE CAMPO}

O objetivo principal desta pesquisa foi identificar e avaliar as práticas compatíveis com a gestão do conhecimento em empresas pertencentes ao setor farmacêutico. $\mathrm{O}$ universo da pesquisa compreende empresas do setor farmacêutico classificadas no guia Exame/Você S.A. "Melhores empresas para você trabalhar" (2004).

A escolha das empresas obedeceu ao critério de maior representatividade. O setor farmacêutico ficou em primeiro lugar em número de empresas eleitas, 18, o melhor resultado já alcançado por um setor entre todos os anos da publicação. Outro fator que influenciou na escolha foi o fato de ser um setor intensivo em conhecimento. Terra (2001) ressalta que o verdadeiro produto da indústria farmacêutica é o conhecimento, e que os comprimidos e medicamentos são apenas embalagens para o conhecimento.

A pesquisa realizada teve, quanto aos fins, características exploratória e descritiva e, quanto aos meios, bibliográfica e documental. Para a coleta de dados foi utilizada a estratégia de levantamento de dados nos sites das empresas e na revista Exame/Você S/A "As 150 melhores empresas para você trabalhar" (2004).

Para a apuração e análise dos dados foi utilizada a técnica de análise de conteúdo, pois esta é, segundo Bardin (1997, p. 105), a técnica apropriada à análise das comunicações. Dentro dos textos analisados buscou-se a unidade tema que, segundo o autor, é "a unidade de significação que se liberta naturalmente de um texto analisado segundo certos critérios relativos à teoria que serve de 
guia à leitura". O autor complementa:

...fazer uma análise temática consiste em descobrir os "núcleos de sentido" que compõem a comunicação e cuja presença, ou frequência de aparição, podem significar alguma coisa para o objetivo analítico escolhido. O tema é geralmente utilizado como unidade de registro para estudar motivações de opiniões, de atitudes, de valores, de crenças, de tendências, etc. (p. 106)

As informações foram agrupadas de forma a avaliar as práticas formais ou institucionais e as práticas informais ou fluidas. Buscou-se identificar as práticas orientadas pelo domínio institucional na estratégia, missão, visão, valores, princípios das empresas, e também nas práticas apuradas pela revista com os funcionários, como por exemplo "avaliação de desempenho" ou "programa de desenvolvimento profissional", que fornece à organização subsídios para prover solução para as lacunas nas competências dos funcionários. As práticas do domínio fluido foram identificadas, principalmente, na pesquisa com os funcionários realizada pela revista Exame/Você S/A (2004), que retrata o ambiente de trabalho.

\section{ANÁLISE E INTERPRETAÇÃO DOS DADOS}

Com base nos dados coletados na pesquisa de campo e na literatura, foi possível fazer algumas reflexões a respeito das práticas compatíveis com a gestão do conhecimento nas empresas estudadas.

\subsection{Caracterização das empresas}

\section{Origem do capital}

Conforme demonstrado na Tabela 1, 28\% das empresas são de capital nacional, e $72 \%$, de capital estrangeiro.

\begin{tabular}{|c|c|c|}
\hline \multirow[b]{2}{*}{ Origem do Capital } & \multicolumn{2}{|c|}{$\begin{array}{c}\text { TABELA } 1 \\
\text { Origem do Capital }\end{array}$} \\
\hline & $\mathrm{N}^{\mathrm{o}}$ de Empresas & Percentual \\
\hline Nacional & 5 & $28 \%$ \\
\hline Estrangeiro & 13 & $72 \%$ \\
\hline Total & 18 & $100 \%$ \\
\hline
\end{tabular}

Fonte: Dados obtidos na pesquisa documental.

\section{Porte}

Como mostrado na Tabela 2, as empresas foram divididas em duas categorias de acordo com o número de empregados. 33\% das empresas possuem de 100 a 499 empregados, e $67 \%$ possuem mais de 500 empregados. 
TABELA 2

Distribuição por porte

\begin{tabular}{ccc}
\hline \hline Porte & $\mathrm{N}^{\circ}$ Empresas & Percentual \\
Média (de 100 a 499 empregados) & 6 & $33 \%$ \\
Grande (acima de 500 & 12 & $67 \%$ \\
$\begin{array}{c}\text { empregados) } \\
\text { Total }\end{array}$ & 18 & $100 \%$ \\
\hline \hline
\end{tabular}

Fonte: Dados obtidos na pesquisa documental. Classificação da CNI (1997).

\section{Presença no guia Exame/Você S/A}

A Tabela 3 apresenta quantas vezes as 18 empresas estiveram presentes no guia Exame/Você S/A melhores empresas para se trabalhar. A presença no guia representa o esforço da empresa no sentido de implantar e manter as melhores práticas de recursos humanos e a consistência destas práticas.

\section{TABELA 3}

\section{Presença no Guia}

\begin{tabular}{ccc}
\hline \hline Número de vezes eleita & $\mathrm{N}^{\circ}$ Empresas & Percentual \\
\hline 1 & 6 & $33 \%$ \\
2 & 2 & $11 \%$ \\
3 & 3 & $17 \%$ \\
4 & 2 & $11 \%$ \\
5 & 2 & $11 \%$ \\
6 & 3 & $17 \%$ \\
\hline \hline
\end{tabular}

Fonte: Dados obtidos na pesquisa documental.

\section{Orientação das práticas compatíveis com gestão do conhecimento}

A Tabela 4 mostra o número de empresas cujas práticas compatíveis com a gestão do conhecimento estão orientadas para o equilíbrio entre o formal e o informal ou o fluido e o institucional.

\section{TABELA 4}

Orientação das práticas - Fluido X Institucional

\begin{tabular}{lcc}
\hline \hline \multicolumn{1}{c}{ Práticas } & $\mathrm{N}^{\mathrm{o}}$ de Empresas & Percentual \\
\hline Orientadas para o equilíbrio entre o fluido e o & 13 & $72 \%$ \\
institucional & & $17 \%$ \\
Orientadas para o domínio institucional & 03 & $00 \%$ \\
Orientadas para o domínio fluido & 02 & $11 \%$ \\
Não foi possível avaliar & 18 & $100 \%$ \\
\hline Total & & \\
\hline \hline
\end{tabular}

Fonte: Dados obtidos na pesquisa documental.

Na pesquisa realizada, contata-se que $72 \%$ das empresas sinalizam que estão preocupadas com o equilíbrio entre o informal e o formal, o fluido e o institucional. Estas práticas espelham a busca para se criar um ambiente propício à criatividade, mantendo o foco nas metas e resultados. Segundo Graham e Pizzo (1998), a orientação para o domínio institucional pode ter um efeito assustador 
sobre a criatividade. $\mathrm{O}$ excesso de controle impede que as novas ideias floresçam. Nesta pesquisa, $17 \%$ das empresas pesquisadas sinalizam estar orientadas para o domínio institucional.

Nenhuma empresa, dentro da população pesquisada, apresentou práticas que nos levem a concluir que ela tenha uma orientação voltada apenas para o domínio fluido.

Em 11\% das empresas pesquisadas não foi possível, através da análise documental, aferir se elas são orientadas para o domínio fluido, para o institucional ou para o equilíbrio entre os dois.

\section{Resumo das práticas compatíveis com a gestão do conhecimento identificadas no estudo}

Na Tabela 5 é apresentado um resumo das principais práticas identificadas nas empresas:

\section{TABELA 5}

\section{Principais práticas identificadas}

\begin{tabular}{|c|c|c|}
\hline Prática & $\mathrm{N}^{\circ}$ de Empresas & Percentual \\
\hline Preocupação com a manutenção de um clima aberto & 15 & $83 \%$ \\
\hline $\begin{array}{l}\text { Processo sistemático para coleta e utilização de ideias e } \\
\text { sugestões }\end{array}$ & 5 & $28 \%$ \\
\hline $\begin{array}{l}\text { Incentivo/subsídio à educação continuada e investimento } \\
\text { em treinamento }\end{array}$ & 10 & $56 \%$ \\
\hline $\begin{array}{l}\text { Importância dada ao conhecimento, aprendizagem e/ou } \\
\text { inovação }\end{array}$ & 15 & $83 \%$ \\
\hline Comunicação interna eficiente & 10 & $56 \%$ \\
\hline Reuniões periódicas com os líderes & 2 & $11 \%$ \\
\hline Acesso livre a departamentos e/ou chefias & 7 & $39 \%$ \\
\hline Programa de desenvolvimento profissional & 8 & $44 \%$ \\
\hline $\begin{array}{l}\text { Estrutura organizacional reduzida, poucos níveis } \\
\text { hierárquicos }\end{array}$ & 1 & $06 \%$ \\
\hline Clareza nas metas organizacionais & 2 & $11 \%$ \\
\hline Investimento em P\&D & 8 & $44 \%$ \\
\hline Trabalho em equipe & 2 & $11 \%$ \\
\hline Rodízio de funções & 9 & $50 \%$ \\
\hline Parcerias estratégicas & 8 & $44 \%$ \\
\hline Integração entre as áreas & 3 & $17 \%$ \\
\hline Autonomia & 3 & $17 \%$ \\
\hline
\end{tabular}

Fonte: Dados obtidos na pesquisa documental.

Uma breve análise das variáveis apresentadas na Tabela 5 é mostrada a seguir:

\section{Clima aberto}


Diversos autores chamam a atenção para a importância do clima organizacional. (DAVENPORT; PRUSAK, 1998; GARVIN, 2001; TERRA, 2001; VASCONCELOS, 2000). Um clima de abertura diz respeito à liberdade e ao aproveitamento dados à criatividade dos membros da organização, podendo limitar ou potencializar a criação e o compartilhamento do conhecimento. Nas empresas pesquisadas, $83 \%$ explicitam a preocupação e a realização de trabalhos para manter um bom clima organizacional, focando a liberdade de expressão, a abertura a críticas e questionamentos, fortalecendo a confiança entre os funcionários.

\section{Processo sistemático para coleta e utilização de ideias e sugestões}

Garvin (2001) chama a atenção para a importância das empresas implementarem programas capazes de estimular a criatividade dos funcionários e motivá-los a contribuir para a melhoria contínua da corporação. Estes programas devem prover meios para incentivar, coletar e utilizar as ideias e sugestões vindas dos funcionários. Neste trabalho, $28 \%$ das empresas possuem este tipo de programa.

\section{Incentivo/subsídio à educação continuada e investimento em treinamento}

A educação continuada é uma preocupação no mundo do trabalho, especialmente por questões relativas à qualidade profissional e à necessidade constante de atualização como exigência prioritária de um novo mercado global, em que os indivíduos representam o principal fator de desenvolvimento. Na pesquisa realizada foi constatado que $56 \%$ das empresas possuem programas de treinamento e práticas de incentivo e subsídio à educação continuada.

Estas práticas são defendidas por vários autores como fundamentais para a criação e o compartilhamento do conhecimento (FLEURY; FLEURY, 2000; GARVIN, 2001; VASCONCELOS, 2000).

\section{Importância do conhecimento, aprendizagem e/ou inovação}

Vários autores comentam a importância da organização, de se tornar explícito o conhecimento e a inovação como algo fundamental para a realização do seu propósito (NONAKA; TAKEUCHI, 1998; NONAKA, 1997; GRAHAM; PIZZO, 1998). Graham e Pizzo (1998) afirmam que as empresas que estão na vanguarda da aprendizagem identificam metas de gestão da aprendizagem ou do conhecimento como elementos explícitos da estratégia corporativa. $\mathrm{Na}$ pesquisa realizada foi possível perceber esta preocupação em $83 \%$ das organizações. Elas reconhecem a importância do conhecimento e/ou da inovação para a realização dos seus propósitos.

\section{Comunicação interna eficiente}

Fleury e Fleury (2000) e Vasconcelos (2000) comentam que o conhecimento precisa circular de maneira rápida e eficiente pela organização. Novas ideias têm maior impacto quando compartilhadas coletivamente do que quando são propriedade de poucas pessoas. Assim, a comunicação interna clara, ágil e objetiva tem papel fundamental para difusão do conhecimento. Além disso, fortalece a confiança, os funcionários bem informados se sentem mais seguros e produzem mais e melhor. Na pesquisa realizada, 28\% das empresas explicitaram ter uma boa comunicação interna.

\section{Reuniões periódicas com a direção}

$\mathrm{Na}$ pesquisa realizada, $11 \%$ das empresas praticam reuniões presenciais periódicas, envolvendo funcionários de todos os níveis hierárquicos, em particular entre líderes e direção da empresa. 
Davenport e Prusak (1998, p. 48) afirmam: "Reuniões face a face costumam ser a melhor maneira de se obter conhecimento."

\section{Acesso livre a departamentos e/ou chefias}

No estudo realizado, $39 \%$ das empresas revelam práticas de acesso livre a departamentos, chefias, gerências e diretorias. Muitos autores como Garvin (2001) e Terra (2001) destacam a importância destas práticas para a construção do meio inovador. Através desta proximidade, a comunicação e as novas ideias fluem com rapidez e naturalidade. Além disso, é incentivada a confiança e a liberdade, propiciando a criação e o compartilhamento do conhecimento.

\section{Programa de desenvolvimento profissional}

Para Terra (2001) e Fleury e Fleury (2000), o desenvolvimento profissional é parte preponderante da gestão do conhecimento e da busca pela competitividade para as empresas. Os programas de desenvolvimento profissional visam desenvolver a potencialização das pessoas necessária ao alto desempenho, promovem o crescimento profissional e a valorização do colaborador. Nesta pesquisa, foi apurado que $44 \%$ das empresas possuem programas de desenvolvimento profissional, com avaliações periódicas e realinhamento das competências necessárias.

\section{Estrutura organizacional reduzida, poucos níveis hierárquicos}

Terra (2001) discorre sobre a importância das novas estruturas da organização. A redução dos níveis hierárquicos promove maior agilidade na tomada de decisão. Na pesquisa realizada apurou-se que apenas uma pequena parcela da amostra, $6 \%$, possui uma estrutura hierárquica reduzida.

\section{Clareza nas metas organizacionais}

No estudo realizado, apenas $11 \%$ das empresas explicitaram a preocupação com a clareza na divulgação das metas organizacionais, a divulgação de onde a empresa está e onde pretende chegar. Diversos autores chamam a atenção para esta prática, pois ela está profundamente relacionada ao comprometimento dos funcionários com os resultados. Quando eles se sentem participantes da decisão, a sua adesão é natural e consequentemente se compromete com os resultados (TERRA, 2001; DAVENPORT; PRUSAK, 1998; SENGE, 1990).

\section{Investimento em P\&D}

Nesta pesquisa, apenas $44 \%$ das empresas citam investimentos em P\&D. Ressaltam-se aqui as observações de Santos (2001) que afirma que, no Brasil e em outros países em desenvolvimento, as empresas transnacionais que atuam no mercado farmacêutico não operam no primeiro e segundo estágios tecnológicos (Pesquisa e Desenvolvimento e Produção de Fármacos). Dessa forma, as inovações inerentes a estes são determinadas internacionalmente. Esses países caracterizam-se, portanto, por serem dependentes de importação de matérias-primas e ausência de $\mathrm{P} \& \mathrm{D}$, mas com um elevado desenvolvimento nas etapas de produção de medicamentos em suas formas finais e no marketing e comercialização, comparáveis aos países desenvolvidos. Portanto, deve-se esperar que os esforços empreendidos para gestão do conhecimento e inovação visem principalmente à redução de custos e à otimização dos processos.

\section{Trabalho em equipe}

Diversos autores citam a importância do trabalho em equipe na vida e no sucesso da organização. É dentro da equipe que o indivíduo cresce, cedendo e recebendo conhecimento, participando da sua criação e compartilhamento (FLEURY; FLEURY, 2000; DAVENPORT; PRUSAK, 1998; NONAKA; TAKEUCHI, 1998). 
$\mathrm{Na}$ pesquisa realizada, apenas $6 \%$ das empresas revelam que praticam e valorizam o trabalho em equipe.

\section{Rodízio de funções}

A prática do rodízio de funções por áreas, unidades e posições na empresa é citada por vários autores como uma das melhores formas de disseminar o conhecimento dentro da empresa (FLEURY; FLEURY, 2000; DAVENPORT; PRUSAK, 1998; NONAKA; TAKEUCHI, 1998; SENGE, 1990; SOUZA NETO, 2004).

Nesta pesquisa, foi identificado que $50 \%$ das empresas pertencentes à amostra praticam o rodízio de funções.

\section{Parcerias estratégicas}

Terra (2001) e Fleury e Fleury (2000) ressaltam a importância das parcerias estratégicas ou alianças para a gestão do conhecimento e a inovação. Estas parcerias visam principalmente à combinação de habilidades e podem ser feitas com clientes, fornecedores, outras empresas, universidades e laboratórios. Nesta pesquisa, $44 \%$ das empresas citam a prática de parcerias como parte da sua estratégia.

\section{Integração entre as áreas}

Cada vez, fica mais difícil que os setores das organizações, isoladamente, dominem todas as informações e conhecimentos para a resolução dos problemas complexos. Departamentos, áreas e equipes precisam trocar, precisam comunicar o que estão fazendo e como estão fazendo. É preciso uma visão comum. A integração entre as áreas promove um ambiente interno onde a informação e o conhecimento fluem livremente, com naturalidade, possibilitando a criatividade, o comprometimento e, principalmente, a criação de uma visão comum (VASCONCELOS, 2000).

Neste trabalho, apenas $17 \%$ das empresas realizam esta prática.

\section{Autonomia}

Alguns autores chamam a atenção para a necessidade da empresa dar autonomia para seus funcionários. A iniciativa deve ser encorajada, bem como a experimentação e a improvisação, e o erro deve ser visto como parte do processo de aprendizagem coletiva. Para estes autores, esta é uma das condições capacitadoras da gestão do conhecimento (NONAKA; TAKEUCHI, 1998; TERRA, 2001).

Na pesquisa realizada, 17\% das empresas fazem alusão à prática de buscar e incentivar a autonomia para que os profissionais realizem as suas tarefas.

\section{CONSIDERAÇÕES FINAIS}

Este trabalho de pesquisa analisou 18 empresas do setor farmacêutico que foram eleitas pela revista Exame/Você S/A "As 150 melhores empresas para você trabalhar" (2004) e objetivou identificar, nestas empresas, as práticas compatíveis com a gestão do conhecimento, através das informações coletadas na revista e nos sites das empresas na internet. Outros objetivos foram avaliar as orientações estratégicas voltadas para a gestão do conhecimento e também avaliar se estas empresas procuram equilibrar a formalidade com a informalidade, conforme proposto por Graham e Pizzo (1998). As práticas informais propiciam um ambiente aberto, descontraído, estimulando a 
criatividade, a iniciativa, a criação e o compartilhamento do conhecimento, um ambiente de tolerância aos erros possibilitando a experimentação e a improvisação, fontes de novas ideias. As práticas formais disciplinam, medem, controlam e não permitem que estas ideias se percam, sendo transformadas em produtos, serviços, melhorias e também, principalmente, que não se perca o foco nas metas dos negócios.

A análise dos resultados revelou que uma das práticas mais presentes nas empresas analisadas é a criação e manutenção de um ambiente aberto, de camaradagem e de estímulo à criatividade e à iniciativa. $83 \%$ das empresas fazem uso desta prática. Chama-se a atenção para o fato de que $83 \%$ da amostra reconhecem e explicitam, seja na estratégia, na missão, na visão, nos valores ou nos princípios organizacionais, a importância do conhecimento, a necessidade de estímulo à aprendizagem e à inovação. Esta prática guia as empresas em todas as suas ações.

O elevado percentual de empresas orientadas para a importância do conhecimento comprova o que foi apurado na análise do equilíbrio das práticas como um todo: em $72 \%$ delas pode ser verificado este equilíbrio. Observou-se que estas orientações são o cerne que sustenta a estrutura de equilíbrio entre o formal e o informal, entre o fluido e o institucional de Graham e Pizzo (1998). De um lado, a fluidez de um ambiente aberto e, de outro, a orientação sistemática do propósito da empresa encravada em valores e princípios.

As empresas pesquisadas mostram uma preocupação com a criação de um ambiente propício à criatividade, ponto de partida para a inovação, principalmente as incrementais, que visam à redução de custos e otimização dos processos. Entretanto, chama a atenção o baixo percentual de empresas que possuem um processo sistemático de coleta e utilização de ideias e sugestões, bem como os também baixos percentuais das práticas de integração entre as áreas, autonomia, trabalho em equipe, clareza nas metas organizacionais, reuniões periódicas com os líderes e adoção de novas estruturas organizacionais, mostrando certa contradição nos resultados.

Outras práticas importantes identificadas pela pesquisa foram: incentivo e/ou subsídio à educação continuada e treinamentos $(56 \%)$, excelência na comunicação interna $(56 \%)$, rodízio de funções (50\%), investimento em P\&D (44\%), programa de desenvolvimento profissional (44\%), parcerias estratégicas com universidades, laboratórios, clientes, fornecedores, outras empresas do mesmo ramo de atividades (44\%) e acesso livre a departamentos e chefias, sem barreiras, com portas abertas (39\%).

As limitações deste trabalho são de diversas ordens. Uma delas diz respeito às informações disponíveis nos sites e na revista Exame "As 150 melhores empresas para você trabalhar" (2004). Estas informações foram publicadas com objetivos diversos e muitas vezes se mostraram vagas. Por isso, vale ressaltar que muitas empresas podem realizar outras práticas que não estão descritas nestes instrumentos e podem também ter práticas ali descritas que não são realizadas de fato.

Para sanar as limitações desta pesquisa e ampliar a discussão do tema, sugere-se que outros estudos sejam efetuados: realização de estudos de caso e pesquisas de campo com algumas destas empresas e realização da mesma pesquisa com outros setores.

\section{REFERÊNCIAS}

BARDIN, Laurence. Análise de conteúdo. Lisboa: Edições 70, 1997.

BROWN, John Seely; DUGUID, Paul. Equilibrismo - Como capturar o conhecimento sem matá-lo. In: APRENDIZAGEM ORGANIZACIONAL/Havard Business Review. Trad. de Cássia Maria Nasser. Rio de Janeiro: Campus, 2001. 
CARVALHO, Rodrigo B. Tecnologia da informação aplicada à gestão do conhecimento. Belo Horizonte: C/Arte, 2003.

CAVALCANTI, Marcos; GOMES, Elisabeth; PEREIRA, André. Gestão de empresas na sociedade do conhecimento. Rio de Janeiro: Campus, 2001.

DAVENPORT, Thomas H.; PRUSAK, Laurence. Ecologia da informação: por que só a tecnologia não basta para o sucesso na era da informação. São Paulo: Futura, 1998.

DAVENPORT, Thomas H.; PRUSAK, Laurence. Conhecimento empresarial. Rio de Janeiro: Campus, 1999.

EXAME/VOCÊ S.A. As 150 melhores empresas para você trabalhar. São Paulo, 2004.

FLEURY, Afonso; FLEURY, Maria Tereza L. Estratégias empresariais e formação de competências. São Paulo: Atlas, 2000.

GARVIN, David A. Construindo a organização que aprende. In: GESTÃO DO CONHECIMENTO/Havard Business Review. Rio de Janeiro: Campus, 2001. p. 50-81.

GRAHAM, A.; PIZZO, V. Uma questão de equilíbrio: estudos de casos na gestão estratégica do conhecimento. In: KLEIN, D. A gestão estratégica do capital intelectual: recursos para a economia baseada no conhecimento. Rio de Janeiro: Qualitymark, 1998. p. 15-39.

NONAKA, Ikujiro; TAKEUCHI, Hirotaka. Criação de conhecimento na empresa: como as empresas japonesas geram a dinâmica da inovação. Rio de Janeiro: Campus, 1998.

NONAKA, Ikujiro. A empresa criadora do conhecimento. In: STARKEY, Ken. Como as organizações aprendem. São Paulo: Futura, 1997. p. 27-43.

SANTOS, Sílvio César Machado dos. Melhoria da equidade no acesso aos medicamentos no Brasil: os desafios impostos pela dinâmica da competição extra-preço. Dissertação (Mestrado) Fundação Oswaldo Cruz, Escola Nacional de Saúde Pública, Rio de Janeiro, 2001.

SENGE, Peter M. A quinta disciplina: arte e prática da organização que aprende. São Paulo: Best Seller, 1990.

SOUZA NETO, José Lourenço de. Gestão do conhecimento em pequenas empresas prestadoras de serviços: fator estratégico para a competitividade. Dissertação (Mestrado) - Faculdades Integradas de Pedro Leopoldo, Pedro Leopoldo, 2004.

TERRA, José Cláudio C. Gestão do conhecimento, o grande desafio empresarial: uma abordagem baseada no aprendizado e na criatividade. São Paulo: Negócio, 2000.

TERRA, José Cláudio C. Gestão do conhecimento: aspectos conceituais e estudo exploratório sobre as práticas de empresas brasileiras. In: FLEURY, Maria T. L.; OLIVEIRA JR., Moacir M. Gestão estratégica do conhecimento. São Paulo: Atlas, 2001. p. 212-241.

VASCONCELOS, M. C. R. L. Cooperação universidadelempresa na pós-graduação: contribuição para a aprendizagem, a gestão do conhecimento e a inovação na indústria mineira. 2000. $257 \mathrm{f}$. Tese (Doutorado em Ciência da Informação) - Escola de Ciência da Informação, Universidade Federal de Minas Gerais, Belo Horizonte, 2000. 